\title{
Characterizing Safety Leadership Based on the Seven Skills of Effective People Model
}

\author{
PAULA NICOLETA NEAG \\ Politehnica University of Timisoara, Romania \\ nicoleta.neag@student.upt.ro
}

\author{
ALIN GAUREANU \\ Politehnica University of Timisoara, Romania \\ alin.gaureanu@student.upt.ro \\ ANCA DRAGHICI \\ Politehnica University of Timisoara, Romania \\ anca.draghici@upt.ro
}

\begin{abstract}
A preventive approach in the field of Occupational Health and Safety (онs) can be successful if it is strongly supported by the safety leadership that is asserted to positively influence safety compliance amongst employees. Studies of safety leadership have focused on the style or behaviour (often transactional or transformational) of the leader rather than on the activities and practices that constitute leadership. Development of safety leadership could not be limited to training programs but rather to coaching and mentoring activities. Started from these considerations, the article proposes an approach based on The Seven Habits of Highly Effective People of Stephen R. Covey (1989) which have been created the research framework for: (1) assessing the actual profile of managers (using the Seven Habits ${ }^{\circledR}$ Profile Self-Scoring) and (2) to structure focus group debates for providing concrete actions, responsibilities and competences associated to each habit in the case of safety leaders. Covey's seven habits framework have been used in a complex study with a sample group of 419 managers from different companies and the results have identified behaviour patterns for highly effective safety leaders.
\end{abstract}

Key words: Stephen Covey, seven habits, occupational health and safety, safety, leadership

(c))Br.SA https://doi.org/10.26493/1854-4231.15.207-219

\section{Introduction}

A preventive approach in the field of oнs can be successful if it is supported by the organization's management. Strong and visible 
leadership skills and the involvement of managers from all hierarchy levels, can impose the right direction of the implementations and can contribute to a real preventive approach aligned with the safety culture strategy. The variety of leadership styles can be applied in a concrete context of the needed organizational behaviour to support safety leaders (Gaureanu et al. 2016; Gaureanu et al. 2018).

A safety leader not only exhibits personal safety behaviours but inspires others to do the same. These are people who not only follow safety procedures in a constructive manner by acting in a proactive and responsible manner for онs. Safety leaders demonstrate the following behaviours habits (Gaureanu et al. 2018):

- Understanding and following safety procedures and regulations.

- Reporting safety issues when they arise.

- Proactively preventing safety issues.

- Implementing new processes to improve safety.

- Encouraging others to take safety seriously.

Safety leaders don't necessarily have to be managers or supervisors; anybody who has positive social influence over their peers and an interest in improving safety across the organization could be considered a safety leader. From the practical perspective, a safety leader should be less like a hall monitor and more like a cultural influencer. The best safety leaders are the people who help their peers improve without them even realizing it's happening. They are the people on the team who others come to for advice about best practices because they know they will get a response that is both correct and useful (Gaureanu, Draghici, and Weinschrott 2019). The main question that arise from these considerations is: How can safety leaders be educated to train more and more potential employees having such behaviour and to better act in their organizations to support safety culture?

The present research will try to answer this complex question by proposing an approach based on The Seven Habits of Highly Effective People of Stephen R. Covey (1989) which have been adapted to the continue creation process of the safety culture in organizations. The develop framework have been tested with a sample group of managers from different companies and results underlined how leadership teaching and coaching programs could be tailored to better perform leadership in oHs. The paper structure consists of the following chapters: (1) research background; (2) presentation of the research methodology; (3) research results and debates; (4) conclusions. 


\section{Research Background}

A BRIEF PRESENTATION OF THE SEVEN HABITS OF HIGHLY EFFECTIVE PEOPLE

Stephen Covey, renowned expert in organizational behaviour and management and author of The Seven Habits of Highly Effective People (1989), spent over 25 years researching and interacting with people to develop a clear understanding of human effectiveness. In his book, Covey (1989) described fundamentals of human effectiveness as internalized principles and patterns of behaviour that express one's character and produce his/her effectiveness or ineffectiveness. The described approach and the proposed behaviour dimensions are considered when teaching and educating personal management, learning how individuals could have developed their life in an effective and efficient manner to get success.

In the following there will be presented, in a synthetic manner, the seven proposed habits of Covey together with their practical implication. This description will create the basis for defining the safety leaders' characteristics and habits for effectiveness.

\section{Habit \#1: Be Proactive}

A clear distinction exists between being proactive and being reactive as indicated by Covey (1989) via the following statement: 'It's not what happens to us, but our response to what happens to us that hurts us' (p. 73). Reactive individuals are victims of their surroundings in the sense that they preoccupy themselves with situations over which they have limited control. On the contrary, proactive individuals accept situations they cannot control, while adhering to their values in response to situations they can control. As such, they are willing and eager to assume the responsibility of initiating change during adversity (Covey 1989). From the practical perspective, being proactive means that a person must control the environment rather than allowing it to control her/him.

\section{Habit \#2: Begin with the End in Mind}

Covey (1989) referred to the value of being cognizant of one's destination, while simultaneously gleaning a greater understanding of one's current. According to Covey (1989), effectiveness 'does not depend solely on how much effort we expend, but on whether or not the effort we expend is in the right jungle' (p. 101). On the path to effectiveness, individuals must learn to adopt and maintain a paradigm through which they view and act on important decisions. According 
to Covey (1989), mission statements represent invaluable tools for providing purpose and direction in pursuit of one's destination. To practice this habit, a person will need to begin every activity or a plan with a vision in her/his mind. This is the only way a person can determine that she/he is on the right way or in the right direction towards you're the desire and plan destination.

\section{Habit \#3: Put First Things First}

As indicated by Covey (1989), managing priorities is essential for personal and collective growth. Establishing and fulfilling priorities requires individuals to 'see through the lens of importance rather than urgency' (Covey 1989, 179). The distinction between 'important' and 'urgent' manifests through the acknowledgement of people. As Covey (1989) aptly articulated, 'People are more important than things' (p. 170). From the practical perspective, first, a person needs to keep her/his focus on end results and relationships and second, to focus on time dimension.

\section{Habit \#4: Think Win/Win}

To illustrate the habit of win/win, Covey (1989) referred to a 'frame of mind' through which an 'abundance mentality' is cultivated ( $p$. 219). In accordance with the latter principle, individuals can optimize their performance and satisfy their wants and needs by striving toward interdependence, collectively developing solutions, and enjoying shared successes. The win-win paradigm supports the idea that instead of seeing life as a competitive arena, rather see it as a cooperative one.

\section{Habit \#5: Seek First to Understand, then to be Understood}

Perhaps one of the most valuable skills highly effective people possess is the ability to communicate with individuals from a variety of cultural and socioeconomic backgrounds. Highly effective people clearly articulate their thoughts and ideas in a relevant and meaningful manner. Moreover, they continually strive to master the art of listening. Listening is an invaluable skill that supersedes humans' capacity for hearing, a basic physiological response. Listening involves hearing with the intent of understanding and empathizing (Covey 1989).

Covey (1989) described the principle of 'diagnosing before prescribing' as a foundation for understanding and addressing individuals' needs and concerns. Highly effective people acknowledge the

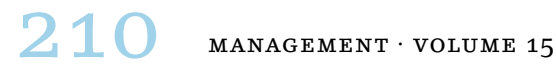


unique characteristics of communities prior to coordinating interventions. Through needs assessments and community profiles, they establish frameworks for mobilizing communities toward shared initiatives.

From the practical perspective and consequences, the successful and healthy interactions with others always demand to understand the other person well that what she/he is trying to say. A person can practice this habit by focusing on what others are trying to say, interpret them well and then give opinion or suggestion. Good listening skills are always necessary to develop and maintain the healthy and positive relationships in every aspect of your life.

\section{Habit \#6: Synergize}

According to Covey (1989), synergy 'catalyses, unifies, and unleashes the greatest powers within people' (p. 262). In other words, synergy is based on the underlying assumption that collaboration between two or more individuals generates effectiveness. At the heart of synergy lies individuals' capacities and willingness to value differences. The differences that make individuals unique enrich the synergistic process and allow learning and creativity to flourish (Covey 1989). The word, 'synergize' is synonymous with the word, 'collaborate.'

From the practical perspective, basically, this habit is about openmindedness and value of teamwork. The reason is that the interaction with others, listening to their opinions and working in a team always give to an individual new insight. All she/he needs to do is understand and value the differences amongst people and strive to construct creative solutions via interactions. Summarizing all the above things, synergize let the person discover the amazing things altogether which are otherwise much less likely to discover by an individual working out on something alone.

\section{Habit \#7: Sharpen the Saw}

According to Covey (1989), 'Renewal is the principle - and the process - that empowers us to move on an upward spiral of growth and change, of continuous improvement' (p. 304). Sharpening the saw represents the mechanism through which all the other habits connect. The process of renewal to which Covey (1989) alluded implies a continual effort to maintain balance and harmony among one's physical, spiritual, mental, and social/emotional well-being and development.

Considering the organizations practice, this habit is about person self-renewing in the following four dimensions: (1) the phys- 
ical dimension (exercising on a regular basis so that the physical body could have the capacity to work and enjoy life); (2) the mental dimension (renewing mental health or sharpening the intellectual abilities to continue expanding her/his mind); (3) the social dimension (empathy development and development of healthy and strong relationships with others); (4) the spiritual dimension (renewing her/his spiritual self to reinforce commitment to individual value system or to proffer leadership to her/his life).

\section{Safety Leadership}

Understanding the importance of safety leadership is critical for any organization that wants to create a real safety culture in the organization with respect to oHs principles, regulations and laws. The approach of development and nurture safety leaders in an organization is associated with the top management commitment to safety culture. According to the literature, some earliest works on leadership style and workplace safety focused on the role of relationshiporiented leadership, such as supervisory consideration (Fleishman, Burtt, and Harris 1955) and managerial concern for subordinates' well-being (Dunbar 1975).

More recent, the behaviour sciences have supported the development of new valences of leadership as transformational and transactional styles are and that have been considered, also in the oHs field as antecedents of safety behaviours (Mullen and Kelloway 2009; Clarke 2013). Furthermore, safety leadership has been considered a valuable way to achieve a safety climate and organization's performance (Pilbeam et al. 2016; Fernández-Muñiz, Montes-Peón, and Vázquez-Ordás 2017; Schwatka et al. 2019).

The research in the literature support the idea that safety leadership training should teach tactical skills that supervisors can use to prevent injuries. Managers and supervisors should learn how to approach others, deliver a safety topic, train people, mentor new hires, pre-plan work, benefit from lessons learned, identify hazards, evaluate events and hold people accountable. That may sound like a fairy-tale list of skills, but it is possible if we deliver safety leadership training that cultivates these critical skills (Lynn 2020; Mearns 2020). Empirical researches and practical studies related to safety leadership have proofed a dominant of women acting in the field and being active and real promoters of oHs in their organizations (FernándezMuñiz, Montes-Peón, and Vázquez-Ordás 2017; Schwatka et al. 2019; Ferri 2019).

Overall, studies of safety leadership have focused on the style

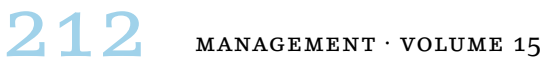


or behaviour (often transactional or transformational) of the leader rather than on the activities and practices that constitute leadership. Moreover, they fail also to account for the influence of context on these practices, following the pattern of the wider leadership literature (Pilbeam et al. 2016). In addition, empirical studies have less discovered the extent to which the reported practices of individuals ascribed as safety leaders ensure organizational compliance with the wider range of safety requirements voluntarily demanded of organizations through adherence to oHSAS 18001.

These brief overview on safety leadership approaches in the literature have provided a gap on still understanding the competences and skills needed by safety leaders, or by safety managers to become leaders in the field of oнs. Further, there will be described the research methodology on applying the seven habits theory of Covey (1989) in the case of safety leadership development.

\section{Research Methodology}

The research aims to define and characterize which are the managers habits (related to their skills and competencies into action) to support oHs by following the suggested Covey's seven habits (1989). The preliminary objective was to characterize managers' oHs habits and to define a feasible way to develop safety leadership skill. The research scenario establishment has been supported by the studies and results published by Pettit and Fetro (2006) and Pahl (2011). They have exploit Covey define framework of seven habits in different organizational context showing two different approaches in the case of health educators (Pettit and Fetro 2006) and for investigating college student levels of autonomy (Pahl 2011), but no other study has been identified in the literature for managers and the oHs context or problematics.

Based on The Seven Habits of Highly Effective People of Stephen R. Covey (1989) there have been defined a protocol for structural interviews and discussions in the context of twenty focus group sessions (each with approximately 20 persons). The protocol includes the following steps (and the related methods and tools included):

1. The presentation of Covey's seven habits (1989), as have been already presented in the previous chapter (20 min). Moderators (authors of these paper) have done the brief presentation, theoretical presentation being combined with examples;

2. Survey based on the questionnaire of Seven Habits ${ }^{\oplus}$ Profile SelfScoring for the managers' behaviour habits self-assessment (as 
previous used by Pahl 2011) (20 min). The fill-up questionnaires have been collected during each of the three focus group sessions and then they were statistically processed;

3. Discussions and emerging ideas to record the actions, responsibilities and competences in the context of oHs management to each habit (20 min). Moderators have followed the list of Covey's seven habits and ask, animate participants in expressing their opinions for actions, responsibilities and competences related to each habit. Responses were collected and then process by a refining process (text analysis) developed with the researchers (authors of the present article).

The present research approach has been developed in September 2019 and applied from November 2019 to February 2020 and it will continue to be developed in implemented with different groups of managers (from all hieratical levels) from different type of companies located in West Region of Romania (Arad and Timisoara, cities). The study target managers because they are (employers) persons that according to oнs regulations have explicit responsibilities for occupational safety.

\section{Research Results and Debates}

SEVEN HABITS PROFILE FOR THE MANAGERS' BEHAVIOUR

Data for the present study were analysed using Predictive Analytics Software (PASw update version of SPSS). The raw data were downloaded, coded, and reverse scored in an Excel spreadsheet and then downloaded into PAsw. Descriptive statistics were created per item related to Covey's seven habits. Each provided the mean, range, variance, and standard deviation. Following descriptive statistics, a test of differences between means was created using a 2 -tailed $t$-test (significance set at $p<0.05$ ) for each Covey habit to study potential differences between respondents' gender. Data were reported in the aggregate, based on the subscales of the Covey Self Profile (Covey) habits.

The internal consistency reliability (Cronbach's Alpha) of the seven habits, as measured by The Seven Habits Self Profile (Covey 1989) was determined for all participants. The Cronbach-Alpha reliabilities of seven habits category reliabilities demonstrated managers from the investigated groups responded to the factors with comparable consistency and at a high enough level of reliability to analyse group data with dependable outcomes.

The research sample population consists of a total number of 42 
TABLE 1 Internal Consistency Reliability of Covey's Seven Habit Scoring Survey

\begin{tabular}{lrrrr}
\hline Variable & $\alpha$ & & Variable & $\alpha$ \\
\cline { 1 - 1 } Be Proactive & 0.71 & & Seek to Understand & 0.79 \\
Begin with End in Mind & 0.70 & & Synergy & 0.74 \\
First things First & 0.79 & & Sharpen the Saw & 0.71 \\
Win/Win & 0.73 & & \\
\hline
\end{tabular}

TABLE 2 Descriptive Statistics

\begin{tabular}{lrrrr}
\hline Measures $(n=419)$ & M & Range & Variance & SD \\
\hline Be proactive & 13.58 & 15 & 6.94 & 2.63 \\
Begin with end in mind & 12.86 & 15 & 9.60 & 3.10 \\
First things first & 12.21 & 15 & 8.48 & 2.91 \\
Win/win & 14.37 & 14 & 6.49 & 2.54 \\
Seek to understand & 14.34 & 13 & 7.08 & 2.66 \\
Synergy & 13.64 & 12 & 6.36 & 2.52 \\
Sharpen the saw & 13.72 & 15 & 7.21 & 2.69 \\
Total & 94.72 & 90 & 205.42 & 14.33 \\
\hline
\end{tabular}

participants $(N=419)$ and according to participant gender they were: 100 male managers (24\%) and 319 female managers (76\%). Table 2 displays descriptive statistics from the Seven Habits Self profile. As can be seen from the research results, the mean and standard deviation for each seven habits were calculated and the following observations were made: 'Be Proactive' $(M=13.58, S D=2.63)$, 'Begin with the End in Mind' ( $M=12.86, S D=3.10)$, 'First Things First' $(M=12.21$, $\mathrm{SD}=2.91)$, 'Win/Win' $(\mathrm{M}=14.37, \mathrm{SD}=2.54)$, 'Seek to Understand' $(M=14.34, S D=2.66)$, 'Synergy' $(M=13.64, S D=2.52)$, 'Sharpen the Saw' $(M=13.72, \mathrm{SD}=2.69)$; the total score is $(\mathrm{M}=94.72, \mathrm{SD}=14.33)$.

Table 3 shows the results of differences between means using a two-tailed $t$-test (significance set at $p<0.05$ ) of gender sample structure, from the Covey Self Profile. The research has underlined the following conclusions:

- Female managers $(n=319, \mathrm{M}=13.21, \mathrm{SD}=3.01)$ measured significantly higher on 'Begin with End in Mind' then males ( $n=$ $100, \mathrm{M}=11.79, \mathrm{SD}=3.07)(t=-4.18, p<0.05)$.

- Female managers $(n=319, \mathrm{M}=14.55, \mathrm{SD}=2.53)$ measured significantly higher on 'Seek to Understand' than males ( $n=100, \mathrm{M}$ $=13.69, \mathrm{SD}=2.94)(t=-2.92, p<0.05)$.

- Female managers $(n=319, \mathrm{M}=12.38, \mathrm{SD}=2.81)$ also measured significantly higher on 'First Things First' than males $(n=100, \mathrm{M}$ $=11.71, \mathrm{SD}=3.15)(t=-2.08, p<0.05)$. 
TABLE 3 Differences between Respondents' Gender:

Results of the Covey Self Profile

\begin{tabular}{|c|c|c|c|c|c|}
\hline \multirow[t]{2}{*}{ Description } & \multicolumn{2}{|c|}{ Male $(n=100)$} & \multicolumn{2}{|c|}{ Female $(n=319)$} & \multirow[t]{2}{*}{$t$} \\
\hline & M & SD & M & SD & \\
\hline Be proactive & $13 \cdot 46$ & 3.07 & 13.62 & 2.47 & -0.56 \\
\hline Begin with end in mind & 11.79 & 3.07 & 13.21 & 3.01 & $-4.18^{* *}$ \\
\hline First things first & 11.71 & 3.15 & 12.38 & 2.81 & $-2.08^{*}$ \\
\hline Win/win & 14.07 & 2.98 & 14.48 & 2.38 & -1.45 \\
\hline Seek to understand & 13.69 & 2.94 & 14.55 & 2.53 & $-2.92^{*}$ \\
\hline Synergy & 13.24 & 2.58 & 13.77 & 2.49 & -1.87 \\
\hline Sharpen the saw & $13 \cdot 32$ & 2.99 & 13.86 & 5.57 & -1.80 \\
\hline Total & 91.28 & 15.52 & 95.87 & 13.74 & $-2.89^{*}$ \\
\hline
\end{tabular}

- 'Be Proactive' showed no significant difference between male managers $(n=100, \mathrm{M}=13.46, \mathrm{SD}=3.07)$ and female managers $(n=319, \mathrm{M}=13.62, \mathrm{SD}=2.47)$.

- 'Win/Win' produced no significant difference between male managers $(n=100, \mathrm{M}=14.07, \mathrm{SD}=2.98)$ and female managers $(n=319, \mathrm{M}=14.48, \mathrm{SD}=2.38)$.

- There was no significant difference in 'Synergy' between male $(n=100, \mathrm{M}=13.24, \mathrm{SD}=2.58)$ and female $(n=319, \mathrm{M}=13.77, \mathrm{SD}$ $=2.49)$ managers.

- There was no significant difference in 'Sharpen the Saw' between male managers $(n=100, \mathrm{M}=13.32, \mathrm{SD}=2.99)$ and female managers $(n=319, \mathrm{M}=13.86, \mathrm{SD}=5.57)$.

As can be seen from the descriptive statistics results, Covey's Self Scoring Profile showed females scoring higher in three habits while there were no significant differences in four habits.

\section{The Behaviour Patterns of Safety Leaderships}

In the final part of each focus group there have been conducted animated discussions with manager participants in the study. They were asked to express their opinions for actions, responsibilities and competences related to each habit and then responses were collected and then process by a refining process (text analysis) developed with the researchers. Table 4 presents the synthesis of this research stage.

In the third phase of the research there have been highlighted that highly effective safety leaders must be innovative, personable, hard-working, and resourceful. If they do not know the answer to a question, they know how to locate valid and reliable sources of 
TABLE 4 The Synthetic Results of the Third Step of the Research (Effective Results of the Focus Groups)

\begin{tabular}{|c|c|}
\hline Habit/chapter & Actions/responsibility (competency) of safety leaders \\
\hline Be proactive & $\begin{array}{l}\text { Gather the needs for онs based on obtained data } \\
\text { Predict the impact of societal value systems on онs programs } \\
\text { Select a variety of communication methods and techniques in } \\
\text { providing oнs information }\end{array}$ \\
\hline $\begin{array}{l}\text { Begin with the } \\
\text { end in mind }\end{array}$ & $\begin{array}{l}\text { Distinguish between behaviours that foster and those that hinder } \\
\text { occupational well-being } \\
\text { Formulate appropriate and measurable program objectives }\end{array}$ \\
\hline $\begin{array}{l}\text { Put first things } \\
\text { first }\end{array}$ & $\begin{array}{l}\text { Gather needs for онs knowledge based on obtained data } \\
\text { Recruit providers, resource people, and potential participants for } \\
\text { support and assistance in program planning } \\
\text { Develop a logical scope and sequence plan for oнs program } \\
\text { Design oнs educational programs consistent with specified } \\
\text { program objectives } \\
\text { Exhibit competence in carrying out planned oнs programs } \\
\text { Carry out evaluation plans }\end{array}$ \\
\hline Think win/win & $\begin{array}{l}\text { Design oHs educational programs consistent with specified } \\
\text { program objectives } \\
\text { Develop plans to assess achievement of онs program objectives }\end{array}$ \\
\hline $\begin{array}{l}\text { Seek first to } \\
\text { understand, } \\
\text { then to be } \\
\text { understood }\end{array}$ & $\begin{array}{l}\text { Develop a plan for coordinating oHs education services } \\
\text { Predict the impact of societal value systems on oнs education } \\
\text { programs } \\
\text { Select a variety of communication methods and techniques in } \\
\text { providing oHs information }\end{array}$ \\
\hline Synergize & $\begin{array}{l}\text { Recruit providers, resource people, and potential participants for } \\
\text { support and assistance in program planning } \\
\text { Develop a plan for coordinating oнs education services } \\
\text { Facilitate cooperation between and among levels of program } \\
\text { personnel } \\
\text { Formulate practical modes of collaboration among oHs actors } \\
\text { (internal-external) Establish effective consultative relationships } \\
\text { with those requesting assistance in solving oHs-related problems } \\
\text { Foster communication between oHs providers and employees }\end{array}$ \\
\hline $\begin{array}{l}\text { Sharpen the } \\
\text { saw }\end{array}$ & $\begin{array}{l}\text { Gather oHs related data and information about social and cultural } \\
\text { environments, growth and development factors, needs, and interests } \\
\text { Interpret results of the oнs program evaluation } \\
\text { Infer implications from findings for future program planning } \\
\text { Utilize computerized oHs information retrieval systems effectively } \\
\text { Interpret and respond to requests for oнs information } \\
\text { Interpret concepts, purposes, and theories of онs }\end{array}$ \\
\hline
\end{tabular}

information in response to the inquiry. Above all, highly effective safety leaders are passionate, caring, and committed to contributing to the betterment of safety culture in organizations. Safety leader is a promising field of research (from the perspective of behaviour sci- 
ences) that continues to prosper and develop. As oHs costs continue to escalate, the role of safety leaders in the prevention of occupational injuries and disease increasingly will become evident. Current and future safety leaders must learn to appreciate the contributions of key leaders who worked diligently to establish credibility for the profession.

\section{Conclusions}

The study underlined that Covey (1989) described the principle of 'diagnosing before prescribing' as a foundation for understanding and addressing individuals' needs and concerns. There have been no studies found in the literature that connect Covey's seven habits with leadership in generally, and with safety leadership, special.

The study has proofed that highly effective safety leaders acknowledge the unique characteristics of organization's communities prior to coordinating interventions. Furthermore, through needs assessments and community profiles, safety leaders establish frameworks for mobilizing other employees toward shared oHs initiatives. The identifies actions, responsibility (competency) of safety leaders (table 1) could be considered as behaviour pattern for this category of employees and they also could be continuous assess and trained for supporting the safety leadership development at the organizational level.

\section{References}

Clarke, S. 2013. 'Safety Leadership: A Meta-Analytic Review of Transformational and transactional Leadership Styles as Antecedents of Safety Behaviours.' Journal of Occupational and Organizational Psychology 86 (1): 22-49.

Covey, S. R. 1989. Seven Habits of Highly Effective People. New York: Simon and Schuster.

Dunbar, R. L. M. 1975. 'Manager's Influence on Subordinates' Thinking about Safety.' Academy of Management Journal 18 (2): 364-69.

Fernández-Muñiz, B., J. M. Montes-Peón, and C. J. Vázquez-Ordás. 2017. 'The Role of Safety Leadership and Working Conditions in Safety Performance in Process Industries.' Journal of Loss Prevention in the Process Industries 50:403-15.

Ferri, A. 2019. 'Women in Safety Leadership.' Professional Safety 64 (8): $13-6$.

Fleishman, E. A., H. E. Burtt, and E. F. Harris. 1955. Leadership and Supervision in Industry. Columbus, он: Ohio State University.

Gaureanu, A., A. Draghici, and H. Weinschrott. 2019. 'Increasing the Quality of Occupational Safety and Health Implementations through 
Awareness Training for Those Involved in Implementing the Safety Observation Report.' Calitatea 20 (s1): 141.

Gaureanu, A., H. Weinschrott, A. Draghici, and A. Jitarel. 2016. 'Knowledge Management Impact on the Occupational Safety and Health Culture in Enterprise.' In Managing Innovation and Diversity in Knowledge Society Through Turbulent Time: Proceedings of the MakeLearn and тілм Joint International Conference, 539-47. Bangkok, Celje, and Lublin: ToKnowPress.

Gaureanu, A., A. Draghici, C. Dufour, and H. Weinschrott. 2018. 'The Organizational Safety Culture Assessment.' In International Conference on Human Systems Engineering and Design: Future Trends and Applications, 728-34. Cham: Springer.

Lynn, D. G. 2020. 'Safety Leadership Training: Nine Safe Habit Tools.' Professional Safety 65 (1): 21.

Mearns, K. J. 2020. 'Safety Leadership and Human and Organisational Factors (ноғ) - Where Do We Go from Here?' In Human and Organisational Factors, edited by B. Journé, H. Laroche, C. Bieder, and C. Gilbert, 15-23. Cham: Springer.

Mullen, J. E., and E. K. Kelloway. 2009. ‘Safety Leadership: A Longitudinal Study of the Effects of Transformational Leadership on Safety Outcomes.' Journal of Occupational and Organizational Psychology 82 (2): 253-72.

Pahl, C. M. 2011. 'Moving through Autonomy toward Interdependence: The Relationship between Chickering and Reisser's Third Vector and Stephen Covey's Seven Habits of Highly Effective People.' Master thesis, Eastern Illinois University.

Pettit, M. L., and J. V. Fetro. 2006. 'The Seven Habits of Highly Effective Health Educators.' Health Educator 38 (1): 3-6.

Pilbeam, C., N. Doherty, R. Davidson, and D. Denyer. 2016. 'Safety Leadership Practices for Organizational Safety Compliance: Developing a Research Agenda from a Review of the Literature.' Safety Science 86:110-21.

Schwatka, N. V., L. M. Goldenhar, S. K. Johnson, M. A. Beldon, J. Tessler, J. T. Dennerlein, M. Fullen, and H. Trieu. 2019. 'A Training Intervention to Improve Frontline Construction Leaders' Safety Leadership Practices and Overall Jobsite Safety Climate.' Journal of Safety Research 70:253-62. 